\title{
Associations of early childhood caries with salivary beta defensin-3 and childhood anemia: a case-control study
}

\author{
Sanam Faheem ${ }^{1 *}$, Shahida Maqsood ${ }^{1}$, Arshad Hasan², Fouzia Imtiaz ${ }^{3}$ Faheem Shaikh ${ }^{4}$ and \\ Waqas Ahmed Farooqui ${ }^{5}$
}

\begin{abstract}
Background: Human beta defensin-3 (HBD-3) is an antimicrobial peptide present in saliva that protects tooth surfaces from microbial attack. These peptides are part of innate immunity so levels may be affected by different systemic diseases like anemia. Therefore, anemia may predispose an affected child to an increased risk of dental caries. The objectives of this study were to determine the association of early childhood caries (ECC) with HBD-3 levels and observe the association of H $\beta$ D-3 levels with childhood anemia.
\end{abstract}

Methods: A total of 80 children admitted in a pediatric medical ward, age 48-71 months, of either sex were included in the study. The included children were categorized as cases (children with ECC $n=40$ ) and controls (children without ECC $n=40$ ). Children were further segregated into the anemic and non-anemic sub-groups based on the hospital record of hemoglobin level. The salivary concentration of HBD-3 was measured by Enzyme-Linked Immuno-sorbent assay (ELISA). IBM SPSS version 20 software was used for statistical analysis. Two sample t-test and one-way ANOVA were used to compare mean values while spearman was used for correlations at $p<0.05$.

Results: The mean Salivary HBD-3 level in cases $(8.87 \pm 4.30)$ was significantly higher $(p=0.042)$ as compared to controls $(7.23 \pm 2.57)$. Salivary HBD-3 level in patients with caries and without anemia was highest $(10.80 \pm 4.50)$ whereas salivary HBD-3 level in the presence of caries and anemia was lowest (6.94 \pm 3.13$)$ amongst all groups. This difference was statistically significant $(p=0.001)$. Salivary HBD-3 level was found to be moderately correlated with cases $(p=0.002)$. An inverse correlation was found between salivary HBD-3 level and anemia $(r=-0.479, p=0.002)$.

Conclusion: Anemia may affect the innate immunity of children, and may result in a decreased level of salivary $H \beta D 3$, thus increasing vulnerability to decay.

Keywords: Early childhood caries, Human beta defensin-3, Anemia

\section{Background}

Dental caries in pre-school children commonly known as early childhood caries (ECC) remains the most prevalent chronic disease in children which has a significant impact

\footnotetext{
*Correspondence: sanam.faheem@duhs.edu.pk

${ }^{1}$ Department of Oral Biology, Dow Dental College, Dow University

of Health Sciences, Karachi, Pakistan

Full list of author information is available at the end of the article
}

on society [1]. ECC was found to be five times as common as asthma and seven times as frequent as hay fever when it was compared with other childhood diseases [2]. Early childhood caries has multifactorial etiology. Cariogenic microorganisms (mutans streptococci and lactobacillus) present in dental plaque are one of the main etiological factors [3]. Despite the role of diet and oral hygiene in its etiology, innate immunity may also play its part in caries development [4]. Previous publications have associated 
innate immunity markers such as lysozymes, lactoferrin [5], immunoglobulins [6], and antimicrobial peptides [79] with ECC [10].

Antimicrobial peptides (AMPs) are a part of the innate immune response that are present in the oral cavity and are important contributors in maintaining the balance between disease and health in the oral cavity. These include beta-defensins that are expressed by oral epithelium, alpha-defensins, secreted by neutrophils, or cathelicidin [10]. They have broad-spectrum antimicrobial activity against gram-positive and negative bacteria, some yeasts, and viruses and are being widely used as potential therapeutic agents especially in the oral cavity where there is a constant exposure of microorganisms [10]. AMPs prevent caries development by inhibiting the growth and adhesion of microorganisms or by inactivating its toxins [11]. These peptides are classified on their structural and biochemical basis. Defensin is a type of AMP with three disulfide bonds [12]. Among other peptides of this group, $\mathrm{H} \beta \mathrm{D}-3$ is important because of its structural and functional diversity and its recent coverage in pharmaceutical applications [13]. This peptide is either expressed constitutively or is inducible, and it contributes to innate immunity by direct bactericidal activity and adaptive immunity through effector and regulatory functions [13]. An Asian study in 2017 reported increased $\mathrm{H} \beta \mathrm{D}-3$ levels in saliva of carious group (6-10 year school children) as compared to healthy controls [8]. Similarly, increased salivary H $\beta$ D-2 and histatin 5 have also been associated with an increased caries experience [9].

Children with a severe form of caries are malnourished due to poor feeding habits or food intake with disturbed sleep patterns due to constant pain [14]. Children experiencing pulpal involvement in at least one tooth can weigh less than those without it [15] and resulting malnutrition may leave a major impact on overall systemic health [16]. If such cases are not treated early, prolonged malnutrition not only makes the child anemic but may also affect salivary gland function by reducing its flow, constituents, and buffering capacity, thus, making a child more prone to decay [14-17]. Anemia is a common public health problem in growing children and there is a strong association between Iron Deficiency Anemia (IDA) and ECC $[17,18]$. Iron deficiency anemia is suggested as the most common nutritional deficiency affecting almost 2 billion people in the world [19].

Many theories have been put forward to explain the above-mentioned relationship. For example, the production of cytokines due to the enhanced inflammatory response of the body in ECC impairs erythropoiesis or prolonged episodes of pain that causes difficulty in chewing /eating and also results in malnutrition which eventually leads to low levels of $\mathrm{Hb} \&$ IDA [20]. Childhood anemia also increases the susceptibility of children towards infection by its effects on defective Interleukin-2 (IL-2) and Interleukin-6 (IL-6) production and thus compromises immunity [21]. Iron has been categorized as an important component of the immune system as its deficiency decreases the bactericidal effects of innate host peptides [22]. Previous researches have reported that early childhood caries may have a direct relationship with H $\beta D$ peptide $[8,9]$. However, an inverse relationship, i.e. children with anemia are perhaps more prone to develop dental caries, may also be true. More specifically, can anemia alter the level of $\mathrm{H} \beta \mathrm{D}-3$ in children in the presence of dental caries? This is because innate immune response may be affected by a systemic disease like anemia? These questions were explored in the present study as many studies have been compiled in a systemic review that has discussed this relationship [18].

Considering two strong associations of ECC with Anemia and ECC with H $\beta D-3$, the purpose of this study was to observe the association of $\mathrm{H} \beta \mathrm{D}-3$ with $\mathrm{ECC}$ considering anemia as a risk factor.

\section{Methods \\ Study design and setting}

This case-control study was conducted in the Pediatric Ward of Ruth K.M.Pfau Civil Hospital Karachi after taking the research approval from the Institutional Review Board (Ref: IRB-1200/DUHS/Approval/2019/).

\section{Sample size}

The sample size of five subjects per group was calculated using PASS version 11 software, based on two independent sample t-test allowing unequal variances with $95 \%$ confidence interval and $80 \%$ power of the test. Mean \pm standard deviation of human beta-defensin in cases (with caries) 2.29 \pm 0.05 and in controls (without caries) $2.15 \pm 0.07$ respectively [9]. Keeping in view low subjects in each group, we increased the sample size to 80 subjects (40 per group).

\section{Study participants}

Both children, with and without caries, were recruited from the Pediatric Ward of Ruth K.M.Pfau Civil Hospital Karachi. Cases included children reporting with ECC in primary dentition with one or more decayed, missing, or filled teeth in any primary tooth in a child of either sex with age between 48 and 71 months. The controls included children without decayed teeth in primary dentition, of either sex of the same age group (48-71 months). However, un-cooperative children, differently-abled children, children older than this age group, or children with systemic disease other than anemia were not included. 
The study population comprised 80 children, 40 children were with caries (ECC) as cases and 40 were without caries (ECC) as controls. Further stratification in cases and controls was performed based on hemoglobin level (taken from their previous medical records) with the reference value [23] $(<11.0 \mathrm{~g} / \mathrm{dl})$ into anemic and $(>11.0 \mathrm{~g} /$ dl) non-anemic groups during statistical analysis. These children, cases, and controls were sub-divided into the following four groups. Cases: Group I (ECC+Anemia+), Group II (ECC+ Anemia-). Controls: Group III (ECCAnemia+) and Group IV (ECC- Anemia-).

Consent was taken from parents at the time of recruitment of children in the study. Demographic details like age and sex with socio-economic data were collected and clinical examination was performed with examination instruments for detection of decayed, missing, and filled tooth index (dmft). Decayed, missing, and filled teeth were counted with related history. The findings were recorded in datasheets. Children were asked not to drink or eat for $30 \mathrm{~min}$ before sample collection.

\section{Saliva collection and quantitative assessment by ELISA}

Unstimulated whole saliva was collected by asking children to sit upright, tilting their heads down, and keeping their mouths open until saliva flooded on the floor of the mouth. Then they were asked to let saliva drool into the falcon tube of $15 \mathrm{ml}$. The procedure was repeated until the required amount of saliva was collected $(4-5 \mathrm{ml})$ [24]. Falcon tubes were kept in crushed ice in disposable glasses. The saliva sample was kept in crushed ice in thermo-pole bags, and in $30 \mathrm{~min}$ was shifted to the lab for centrifugation. All samples were centrifuged to clear saliva at $4500 \mathrm{rpm}$ at $4{ }^{\circ} \mathrm{C}$ for $15 \mathrm{~min}$. The supernatant was collected by using a micropipette. A $0.3 \mathrm{ml}$ was collected into Eppendorf tubes and stored in the freezer $\left(-20^{\circ} \mathrm{C}\right)$ until further analysis $[22,24,25]$. All the procedures were performed under relevant guidelines [26, 27].
The level of H $\mathrm{H}$ D-3 in saliva was estimated by using an Enzyme-Linked Immuno-sorbent assay (ELISA) kit (Human Beta Defensin 3 ELISA kit Cat. No E3240Hu) from Bioassay Technology Laboratory.

\section{Statistical analysis}

IBM SPSS version 20 software was used to analyze data. Statistical analysis was conducted based on data distribution by using two independent samples t-test to compare the mean $\mathrm{H} \beta \mathrm{D}-3$ level in cases and controls. One way-ANOVA was used to compare mean values of four stratified groups of cases and controls. A post hoc test (Tukey's test) was used for the pairwise comparison of group II (children with caries and without anemia) with the remaining three groups. Mann-Whitney test was used to find the difference in the $\mathrm{dmft}$ index in different study groups of ECC and anemia. Spearman correlation was used for observing the correlation between $\mathrm{H} \beta \mathrm{D}-3$ with ECC \& H $\beta$ D-3 with anemia.

\section{Results}

Basic demographic statistics are presented in Table 1, which shows the distribution of the population by age and sex into different study groups. The age group included children from $48-71$ months with a mean value of $65.0 \pm 4.4$. The mean salivary $\mathrm{H} \beta \mathrm{D}-3$ level in cases $(8.87 \pm 4.30)$ was significantly higher $(p=0.042)$ as compared to controls $(7.23 \pm 2.57)$ as presented in Table 2 . When cases and controls were further stratified into four groups, salivary H $\beta \mathrm{D}-3$ level in the presence of caries and anemia (group I) was the lowest $(6.94 \pm 3.13, p=0.001)$ and was highest $10.80(4.50)$ in children with caries and without anemia (group II) amongst all groups as presented in Table 3. The pairwise analysis of groups further strengthened this relationship and revealed that the mean $\mathrm{H} \beta \mathrm{D}-3$ level of group II was highest among all groups.

The association of dmft with ECC and anemia is presented in Table 4. The dmft score of anemic children

Table 1 Descriptive statistics of sex, age and $\mathrm{Hb}$

\begin{tabular}{llllll}
\hline Characteristics & $\mathbf{n = 8 0 ( \% )}$ & $\begin{array}{l}\text { Anemic: non-anemic } \\
\text { (ratio) }\end{array}$ & ECC: non-ECC (ratio) & $\begin{array}{l}\text { Cases (with ECC) } \\
\mathbf{n}=\mathbf{4 0}(\%)\end{array}$ & $\begin{array}{l}\text { Controls } \\
\text { (without } \\
\text { ECC) } \\
\mathbf{n}=\mathbf{4 0}(\%)\end{array}$ \\
\hline Sex & & & & & \\
Female & $47(58.7)$ & $22: 25$ & $18: 29$ & $29(72.5 \%)$ & $18(45 \%)$ \\
Male & $33(41.25)$ & $18: 15$ & $22: 11$ & & $22(55 \%)$ \\
Age $($ months) & & & & & \\
Hb level ${ }^{a}(\mathrm{~g} / \mathrm{dl})$ & $65.0 \pm 4.4$ & & & & \\
\hline
\end{tabular}

$\mathrm{Hb}$, Hemoglobin; ECC, Early childhood caries

${ }^{a}$ Values are represented as Mean \pm SD 
Table 2 Salivary HBD-3 levels in different study groups

\begin{tabular}{lccc}
\hline Study groups & $\mathbf{n}=\mathbf{8 0}(\%)$ & $\begin{array}{l}\text { HBD-3 levels } \\
\text { Mean } \pm \text { SD }\end{array}$ & t-test $(\boldsymbol{p}$-value) \\
& & & \\
\hline ECC & & \\
Cases (with ECC) & $40(50)$ & $8.87 \pm 4.30$ & $2.064(0.042)^{\mathrm{a}}$ \\
Controls (without ECC) & $40(50)$ & $7.23 \pm 2.57$ & \\
Anemia & & & \\
With anemia & $40(50)$ & $7.15 \pm 2.82$ & $-2.482(0.015)^{\mathrm{a}}$ \\
Without anemia & $40(50)$ & $9.02 \pm 3.96$ & \\
Age groups & & & \\
48-59 Months & $22(27.5)$ & $8.31 \pm 3.67$ & $0.730^{\mathrm{b}}$ \\
60-71 Months & $58(72.5)$ & $7.95 \pm 3.62$ & \\
Gender & & & \\
Males & $33(41.25)$ & $7.54 \pm 2.67$ & $0.292^{\mathrm{a}}$ \\
Females & $47(58.75)$ & $8.41 \pm 4.14$ & \\
\hline
\end{tabular}

${ }^{a}$ t-test

${ }^{\mathrm{b}}$ Mann whitney test

among cases (group I) was higher $(6.20 \pm 1.73)$ as compared to non-anemic children (group II). This difference was statistically significant $4.257(0.000)$ (Table 4).

The level of salivary HBD-3 and anemia between cases and control was found to be negatively correlated with cases $(r=-0.479, p=0.002)$ (Table 5). An inverse correlation was found between salivary $\mathrm{H} \beta \mathrm{D}-3$ level \& anemia $(\mathrm{r}=-0.262, p=0.019)$, which explains the role of anemia in affecting innate immunity peptides (Table 5). When HBD-3 was correlated with ECC separately, a weak correlation was found $(\mathrm{r}=0.12, p=0.294)$.

\section{Discussion}

This research is the first original research to observe the effects of anemia on salivary levels of HBD-3 in association with ECC. Our results suggest that although the presence of caries may increase the salivary levels of $\mathrm{H} \beta \mathrm{D}-3$, the concomitant presence of anemia with caries may actually cause a reduction in these protective peptides. This research presented a correlation between ECC, H $\beta$ D-3, and anemia when all three variables were compared together. The results showed high levels of peptides in children with ECC (cases) as compared to children without ECC (controls). Upon further stratification (on basis of anemia) of cases \& controls into four subgroups, it was found that group II from cases had the highest levels of peptides as compared to all other groups. Whereas, the levels of peptides in group I were the lowest as compared to the other three groups demonstrating that being anemic reduces the levels of peptides.

The present research showed that cases had higher levels of $\mathrm{H} \beta \mathrm{D}-3$ as compared to controls, which agrees with previous research findings of Indrawati et al. and Jurczak et al. [8, 9]. However, other peptides have also been associated with ECC in past with contrasting results. Indrawati reported a greater expression of $\mathrm{H} \beta \mathrm{D}-1$ in caries-affected children when all three beta-defensins were compared [8]. Jurczak et al. discovered increased levels of $\mathrm{H} \beta \mathrm{D}-2$ and histatin 5 . Joly et al. used radial diffusion to test the antimicrobial activity of $\mathrm{H} \beta \mathrm{D}-2$ and $\mathrm{H} \beta \mathrm{D}-3$ against a variety of oral micro-organisms and recognized $\mathrm{H} \beta \mathrm{D}-3$ with higher antimicrobial activity as compared to H HD-2 [28]. While Davidopouloou et al. [7] \& Malcolm et al. found high levels of cathelicidin LL-37 [29]. Renulka et al. described the role of the $\beta$-defensins

Table 3 Salivary H $\beta D$-3 levels among different study groups

\begin{tabular}{|c|c|c|c|}
\hline Groups & Mean (SD) & $95 \%$ C.I & $P$-value ${ }^{\text {b }}$ \\
\hline I (children with ECC and Anemia) & $6.94(3.13)$ & $5.4-8.4$ & $0.001^{b}$ \\
\hline II (children with ECC but without Anemia) & $10.80(4.50)$ & $8.7-12.9$ & \\
\hline III (children without ECC but with Anemia) & $7.22(2.87)$ & $5.8-8.5$ & \\
\hline IV (children without ECC and Anemia) & $7.25(2.30)$ & $6.1-8.3$ & \\
\hline \multicolumn{4}{|c|}{$\begin{array}{l}\text { Comparison of group II(children with ECC and without Anemia) with all } \\
\text { other groups by Tukey/HSD test }\end{array}$} \\
\hline \multicolumn{4}{|l|}{ Mean difference } \\
\hline Group I (children with ECC and Anemia) & $3.866^{\mathrm{a}}$ & $0.002^{c}$ & \\
\hline Group III (children without ECC but with Anemia) & $3.579^{a}$ & $0.005^{c}$ & \\
\hline Group IV (children without ECC and Anemia) & $3.579^{a}$ & $0.006^{c}$ & \\
\hline
\end{tabular}

$\mathrm{SD}$, standard deviation; $\mathrm{Cl}$, confidence interval

a Mean difference

${ }^{\mathrm{b}}$ One way anova

c Post Hoc Tukey test 
Table 4 Dmft index in different study groups

\begin{tabular}{|c|c|c|}
\hline Study groups & $\begin{array}{l}\text { Dmft } \\
\text { Median (IQR) }\end{array}$ & $p$-value ${ }^{\mathrm{a}}$ \\
\hline \multicolumn{3}{|l|}{ ECC } \\
\hline Carious & $5.0(4.0-6.8)^{b}$ & $<0.001^{\mathrm{a}}$ \\
\hline Non-carious & $0.5(0-1.0)^{b}$ & \\
\hline \multicolumn{3}{|l|}{ Anemia } \\
\hline Anemic & $2.5(1.0-6.75)^{\mathrm{b}}$ & $0.134^{\mathrm{a}}$ \\
\hline Non-anemic & $2.5(0.0-4.0)^{b}$ & \\
\hline Cases (with ECC) & Mean \pm SD & t-test $\left(p\right.$-value $\left.{ }^{c}\right)$ \\
\hline \multicolumn{3}{|c|}{ Dmft score for the children with and without anemia in children with caries } \\
\hline Group I (children with ECC and Anemia) & $6.20 \pm 1.73$ & $4.257(0.000)^{c}$ \\
\hline Group II (children with ECC without Anemia) & $4.35 \pm 0.88$ & \\
\hline
\end{tabular}

Table 5 Spearman correlation( $r$ ) of HßD-3 with different study groups

\begin{tabular}{lr}
\hline H $\beta$ D-3 with & R $(\boldsymbol{P} \text {-value })^{\mathbf{a}}$ \\
\hline Cases & $-0.479(0.002)^{\mathrm{a}}$ \\
Controls & $0.017(0.919)^{\mathrm{a}}$ \\
Anemia & $-0.262(0.019)^{\mathrm{a}}$ \\
\hline
\end{tabular}

${ }^{a}$ Spearman correlation

gene, which is connected to both low and high-risk caries [30]. Defensins are a part of a small arginine-rich peptide family, and arginine in its free or associated form shows strong protective property against caries [31]. Hence, increased levels of peptides are associated with increase caries incidence.

Our findings show that the dmft index of anemic children $(6.20 \pm 1.73)$ was higher as compared to non-anemic children ( $4.35 \pm 0.88)$ (Table 4$)$, which may be attributed mainly to the dietary patterns and other factors affecting the overall health of these children. These results were in agreement with previous findings [32].

Our study is perhaps the first to concurrently observe the effects of anemia on salivary levels of $\mathrm{H} \beta \mathrm{D}-3$ in association with ECC. The two-way relationship between anemia \& ECC was previously supported by many researchers. Due to a reduced amount of red blood cells or low hemoglobin levels at a suboptimal level, cells or tissues are unable to maintain normal physiological function that relies on micronutrients [33]. Hence anemia not only affects the physical and mental growth of the child but also affects the defense system of the oral cavity. It weakens the immunity of a child to fight against microorganisms making the child more prone to infections and decay [19]. Previous researches have addressed this significant inverse correlation between anemia and caries incidence [19]. Bansal et al. and Koppal et al. reported that children with lower hemoglobin levels have a high incidence of caries [17]. Abdallah et al. also associated a higher dmft index with decreasing hemoglobin level [32]. Babu et al. also found an inverse significant relationship between serum hemoglobin level and ECC [34]. Tang et al. found $46 \%$ of children suffering from Iron deficiency anemia (IDA) in their research on ECC [35]. Shaoul et al. also found a strong correlation between ECC and IDA, their results showed that treating carious lesions on time improves iron deficiency in children [36]. Another research concluded that children with severe early childhood caries appear to have significantly lower hemoglobin levels with greater odds of developing IDA as compared to caries-free children [32]. Anemia occurs commonly because of inadequate feeding practices, micronutrient deficiency, and frequent infections [37]. IDA is most common in developing countries, which affects nonspecific immunity in many ways. Iron is important for proper cell differentiation and growth. It is an essential component of the proper enzymatic functions of immune cells. It is needed for regulation in cytokine production and the mechanism of the second messenger system. Hence, its deficiency is considered important in molecular and cellular defects responsible for immune deficiency [38].

\section{Strengths and limitations}

We have determined the relationship of salivary levels of HBD-3 in cases and controls based on our study design. We have shown that cases (children with ECC) 
have higher levels of the peptide as compared to controls (children without ECC). But can this approach be useful in assessing the risk of caries in children as a predictive tool and can it prevent the progression of the disease? These questions can be the basis of future research. This research, however, has proposed the role of anemia in children as anemic children with caries had the lowest level of peptides.

There may be some limitations in this study, the present research had a small sample size, and, therefore, to extrapolate the results to the general public and to truly realize the potential of this peptide as a diagnostic tool, studies with a larger sample size may be performed. Parental education and attitude also influence the feeding practices and oral hygiene habits of children. Apart from salivary immune components, these factors are also very important for the propagation of caries because ECC is a multifactorial disease and is influenced by multiple factors including social and behavioral factors. The present research lacks data on nutrition, their feeding and oral hygiene habits, and the influence of parents in all study groups. Selection bias is one of a major weakness of case-control study design due to lack of random sampling however was partially addressed by selecting the controls from the same pool of a population from where the cases were selected as almost all patients in the present research were from the low socioeconomic strata as all the samples were collected from government sector hospitals.

\section{Conclusions}

The following conclusions may be drawn within the limitations of this study:

The H $\beta \mathrm{D}-3$ level increased with increasing caries incidence. Children experiencing anemia and ECC concomitantly had the lowest level of peptides showing that anemia affects innate immunity, which may increase vulnerability to decay in children under the age of 71 months. However, H $\beta \mathrm{D}-3$ alone cannot be considered as a biomarker to measure the risk of caries as ECC and anemia both are multifactorial diseases.

\section{Abbreviations \\ ECC: Early childhood caries; Hb: Hemoglobin; IDA: Iron deficiency anemia; HBD: Human beta defensins; AMPs: Anti-microbial peptides; WHO: World Health Organization; DMFT: Decayed missing filled teeth; IL: Interleukin.}

\section{Acknowledgements}

We would like to thank all the participants who cooperated with us, without whom this study would not have been possible.

\section{Authors' contributions}

SF was a principal investigator and a major contributor in data collection, manuscript writing, and literature search. SM \& AH were co-investigator, who assisted in the selection of titles, analysis, and interpretation of data. Fl was a co-investigator and a contributor in study settings for ELISA related to Lab work. FS was a co-investigator and a contributor in drafting, data entry, and its analysis. WAF was a co-investigator and a major contributor in statistics. All authors have read and approved the manuscript.

\section{Funding}

The research did not receive any specific grant from funding agencies in the public, commercial or not-for-profit sectors.

\section{Availability of data and materials}

The datasets used and/or analyzed during the current study are available from the corresponding author on reasonable request.

\section{Declarations}

\section{Ethics approval and consent to participate}

This study was approved by the Institutional Review Board of Dow University of Health Sciences (Ref: IRB-1200/DUHS/Approval/2019). Written informed consent was taken from the parents of all participants according to Helsinki's declaration.

\section{Consent for publication \\ Not applicable.}

\section{Competing interests}

The authors declare that they have no competing interests.

\section{Author details}

${ }^{1}$ Department of Oral Biology, Dow Dental College, Dow University of Health Sciences, Karachi, Pakistan. ${ }^{2}$ Department of Operative Dentistry, Dow Dental College, Dow University of Health Sciences, Karachi, Pakistan. ${ }^{3}$ Department of Biochemistry Dow Medical College, Dow University of Health Sciences, Karachi, Pakistan. ${ }^{4}$ London Dental Clinics \& Dental Implants, 41-C Badar Commercial Street 10, Phase 5, Badar Commercial DHA, Karachi, Pakistan. ${ }^{5}$ Department of Research, School of Public Health, Dow University of Health Sciences, Karachi, Pakistan.

Received: 21 December 2020 Accepted: 8 September 2021 Published online: 14 September 2021

\section{References}

1. Kirthiga M, Murugan M, Saikia A, Kirubakaran R. Risk factors for early childhood caries: a systematic review and meta-analysis of case control and cohort studies. Pediatr Dent. 2019;41(2):95-112.

2. Chen KJ, Gao SS, Duangthip D, Lo EC, Chu CH. Prevalence of early childhood caries among 5-year-old children: a systematic review. J Investig Clin Dent. 2019;10(1):12376.

3. Begzati A, Berisha M, Mrasori S, Xhemajli-Latifi B, Prokshi R, Haliti F, Maxhuni V, Hysenaj-Hoxha V, Halimi V. Early childhood caries (ECC)_etiology, clinical consequences and prevention. Emerg Trends Oral Health Sci Dent. 2015:31.

4. Navarra CO, Robino A, Pirastu N, Bevilacqua L, Gasparini P, Di Lenarda R, Crovella S. Caries and innate immunity: DEFB1 gene polymorphisms and caries susceptibility in genetic isolates from north-eastern Italy. Caries Res. 2016;50(6):589-94.

5. Moslemi M, Sattari M, Kooshki F, Fotuhi F, Modarresi N, Sadrabad ZK, Shadkar MS. Relationship of salivary lactoferrin and lysozyme concentrations with early childhood caries. J Dent Res Dent Clin Dent Prospects. 2015;9(2):109.

6. de Farias DG, Bezerra ACB. Salivary antibodies, amylase and protein from children with early childhood caries. Clin Oral Invest. 2003;7(3):154-7.

7. Davidopoulou S, Diza E, Menexes G, Kalfas S. Salivary concentration of the antimicrobial peptide LL-37 in children. Arch Oral Biol. 2012;57(7):865-9.

8. Indrawati $R$, Wahjuningrum DA, Lutfi M, Soesiawan A, Pradopo S: Increased levels of human B defensinsin childs with dental caries. 2017.

9. Jurczak A, Kościelniak D, Papież M, Vyhouskaya P, Krzyściak W. A study on $\beta$-defensin-2 and histatin-5 as a diagnostic marker of early childhood caries progression. Biol Res. 2015;48(1):61. 
10. Astuti ESY, Sukrama IDM, Mahendra AN. Innate immunity signatures of early childhood caries (ECC) and severe early childhood caries (S-ECC). Biomed Pharmacol J. 2019;12(3):1129-34.

11. Sruthi K, Yashoda R, Manjunath PP. Diagnostic potential of saliva as a biomarker in early childhood caries: a review. Children. 2019;11(12):14.

12. Dale BA, Tao R, Kimball JR, Jurevic RJ. Oral antimicrobial peptides and biological control of caries. In: BMC oral health: 2006: Springer; 2006: S13.

13. Dhople V, Krukemeyer A, Ramamoorthy A. The human beta-defensin-3, an antibacterial peptide with multiple biological functions. Biochim Biophys Acta. 2006;1758(9):1499-512.

14. Folayan MO, El Tantawi M, Schroth RJ, Vukovic A, Kemoli A, Gaffar B, Obiyan M. Associations between early childhood caries, malnutrition and anemia: a global perspective. BMC Nutrition. 2020;6(1):1-8.

15. Acs G, Lodolini G, Kaminsky S, Cisneros GJ. Effect of nursing caries on body weight in a pediatric population. Pediatr Dent. 1992;14(5):303.

16. Gaur S, Nayak R. Underweight in low socioeconomic status preschool children with severe early childhood caries. J Indian Soc Pedodont Prevent Dent. 2011;29(4):305

17. Bansal K, Goyal M, Dhingra R. Association of severe early childhood caries with iron deficiency anemia. J Indian Soc Pedodont Prevent Dent. 2016;34(1):36.

18. Hashemi A, Bahrololoomi Z, Salarian S. Relationship between early childhood caries and anemia: a systematic review. Iran J Pediatric Hematol Oncol. 2018:8(2):126-38.

19. Bahdila D, Markowitz K, Pawar S, Chavan K, Fine DH, Velliyagounder K. The effect of iron deficiency anemia on experimental dental caries in mice. Arch Oral Biol. 2019.

20. Subramaniam G, Girish M. Iron deficiency anemia in children. Indian J Pediatr. 2015;82(6):558-64

21. Mullick S, Rusia U, Sikka M, Faridi M. Impact of iron deficiency anaemia on T lymphocytes \& their subsets in children. Indian J Med Res. 2006;124(6):647-54

22. Van Nieuw AA, Bolscher JG, Veerman EC. Salivary proteins: protective and diagnostic value in cariology? Caries Res. 2004;38(3):247-53.

23. WHO W. The global prevalence of anaemia in 2011. Geneva: World Health Organization. 2015 .

24. Lee J, Garon E, Wong D. Salivary diagnostics. Orthod Craniofac Res. 2009;12(3):206-11.

25. Bellagambi FG, Lomonaco T, Salvo P, Vivaldi F, Hangouët M, Ghimenti S, Biagini D, Di Francesco F, Fuoco R, Errachid A. Saliva sampling: methods and devices. An overview. TrAC Trends Anal Chem. 2020;124:115781.

26. Henson BS, Wong DT. Collection, storage, and processing of saliva samples for downstream molecular applications. In: Oral Biology. Springer; 2010. p. 21-30.
27. Bhattarai KR, Kim H-R, Chae H-J. Compliance with saliva collection protocol in healthy volunteers: strategies for managing risk and errors. Int J Med Sci. 2018;15(8):823.

28. Joly S, Maze C, McCray PB, Guthmiller JM. Human $\beta$-defensins 2 and 3 demonstrate strain-selective activity against oral microorganisms. J Clin Microbiol. 2004:42(3):1024-9.

29. Malcolm J, Sherriff A, Lappin DF, Ramage G, Conway DI, Macpherson L, Culshaw S. Salivary antimicrobial proteins associate with age-related changes in streptococcal composition in dental plaque. Mol Oral Microbiol. 2014;29(6):284-93.

30. Piekoszewska-Ziętek P, Turska-Szybka A, Olczak-Kowalczyk D. Salivary proteins and peptides in the aetiology of caries in children: systematic literature review. Oral Dis. 2019;25(4):1048-56.

31. Ribeiro TR, Dria KJ, de Carvalho CBM, Monteiro AJ, Fonteles MC, de Moraes CK, Fonteles CSR. Salivary peptide profile and its association with early childhood caries. Int J Pediatr Dent. 2013;23(3):225-34.

32. Abdallah MA, Abed HH, Hamza G, Alsahafi EN. The association between dmft index and haemoglobin levels in 3-6 year-old Saudi children with anaemia: a cross sectional study. J Taibah Univ Med Sci. 2016;1 1(1):72-6.

33. Schroth RJ, Levi J, Kliewer E, Friel J, Moffatt ME. Association between iron status, iron deficiency anaemia, and severe early childhood caries: a case-control study. BMC Pediatr. 2013;13(1):22.

34. Babu NV, Bhanushali PV. Evaluation and association of serum iron and ferritin levels in children with dental caries. J Indian Soc Pedodont Prevent Dent. 2017;35(2):106.

35. Tang R-S, Huang M-C, Huang S-T. Relationship between dental caries status and anemia in children with severe early childhood caries. Kaohsiung J Med Sci. 2013;29(6):330-6.

36. Shaoul R, Gaitini L, Kharouba J, Darawshi G, Maor I, Somri M. The association of childhood iron deficiency anaemia with severe dental caries. Acta Paediatr. 2012;101(2):e76-9.

37. Perkins DJ, Were T, Davenport GC, Kempaiah P, Hittner JB, Ong'echa JM. Severe malarial anemia: innate immunity and pathogenesis. Int J Biol Sci. 2011;7(9):1427.

38. Beard JL. Iron biology in immune function, muscle metabolism and neuronal functioning. J Nutr. 2001;131(2):568S-580S.

\section{Publisher's Note}

Springer Nature remains neutral with regard to jurisdictional claims in published maps and institutional affiliations.
Ready to submit your research? Choose BMC and benefit from:

- fast, convenient online submission

- thorough peer review by experienced researchers in your field

- rapid publication on acceptance

- support for research data, including large and complex data types

- gold Open Access which fosters wider collaboration and increased citations

- maximum visibility for your research: over $100 \mathrm{M}$ website views per year

At BMC, research is always in progress.

Learn more biomedcentral.com/submissions 